Article

\title{
Chemotaxonomic Characterization and in-Vitro Antimicrobial and Cytotoxic Activities of the Leaf Essential Oil of Curcuma longa Grown in Southern Nigeria
}

\section{Emmanuel E. Essien 1,*, Jennifer Schmidt Newby ${ }^{2}$, Tameka M. Walker ${ }^{2}$, William N. Setzer ${ }^{2}$ and Olusegun Ekundayo ${ }^{3}$}

1 Department of Chemistry, University of Uyo, Akwa Ibom State 520101, Nigeria

2 Department of Chemistry, University of Alabama in Huntsville, Huntsville, AL 35899, USA;

E-Mails: jennifer.newby315@gmail.com (J.S.N.); Ivygrad08@yahoo.com (T.M.W.); wsetzer@chemistry.uah.edu (W.N.S.)

3 Department of Chemistry, University of Ibadan, Ibadan 200284, Nigeria;

E-Mail: oekundayo@yahoo.com

* Author to whom correspondence should be addressed; E-Mail: emmaflowus1@yahoo.co.uk; Tel.: +234-80-3368-3424.

Academic Editors: Lutfun Nahar, Norazah Basar and Satyajit D. Sarker

Received: 11 November 2015 / Accepted: 14 December 2015 /Published: 21 December 2015

\begin{abstract}
Curcuma longa (turmeric) has been used in Chinese traditional medicine and Ayurvedic medicine for many years. Methods: The leaf essential oil of C. longa from southern Nigeria was obtained by hydrodistillation and analyzed by gas chromatography-mass spectrometry (GC-MS). The essential oil was screened for in vitro antibacterial, antifungal, and cytotoxic activities. The major components in $C$. longa leaf oil were ar-turmerone (63.4\%), $\alpha$-turmerone (13.7\%), and $\beta$-turmerone (12.6\%). A cluster analysis has revealed this to be a new essential oil chemotype of $C$. longa. The leaf oil showed notable antibacterial activity to Bacillus cereus and Staphylococcus aureus, antifungal activity to Aspergillus niger, and cytotoxic activity to Hs 578T (breast tumor) and PC-3 (prostate tumor) cells. The ar-turmerone-rich leaf essential oil of C. longa from Nigeria has shown potent biological activity and therapeutic promise.
\end{abstract}

Keywords: Curcuma longa; essential oil composition; ar-turmerone; $\alpha$-turmerone; $\beta$-turmerone; antimicrobial; cytotoxic 


\section{Introduction}

Curcuma longa L. (syn. C. domestica Vahl.) is a perennial rhizomatous herb of the family Zingiberaceae. The rhizome is the source of turmeric, which has use as a condiment and coloring agent in medicines, confectionery and curry powder [1]. Turmeric has a long history of traditional use in the Chinese and Ayurvedic systems of medicine, particularly as an anti-inflammatory agent [2], and for the treatment of biliary disorders, anorexia, coryza, cough, diabetic wounds, hepatic disorders, rheumatism and sinusitis [1]. The powdered rhizome is used externally as an antiseptic [3] and taken internally to cure gastritis [4]. The rhizome volatiles have been extensively studied (see, for example [5-8]), and there have been previous reports on the leaf essential oil compositions [9-26]. Research has shown that the quantitative essential oil composition is widely influenced by the genotype, ontogenic development, and environmental and growing conditions [27-29]. It also implies the possibility of different medicinal uses of the same plant species grown in different regions [30]. This paper reports the chemical constitution of the leaf essential oil of $C$. longa grown in the southern part of Nigeria and its antimicrobial effects and anti-neoplastic potential.

\section{Experimental Section}

\subsection{Plant Material}

Fully grown leaves of $C$. longa were collected from plants cultivated in the village of Mbaiso, Ikot Ekpene Local Government Area of Akwa Ibom State, Nigeria, in the month of October. Plant materials were authenticated by F. Usang of the Forest Research Institute of Nigeria (FRIN), Ibadan, where voucher specimens were deposited under FHI 106920. The essential oil was obtained by hydrodistillation $(4 \mathrm{~h})$ of the air-dried plant leaves using a Clevenger-type apparatus in accordance with the British Pharmacopoeia [31]. The leaf oil was dried over sodium sulfate and kept in refrigeration $\left(4{ }^{\circ} \mathrm{C}\right)$ after estimation of percentage yield.

\subsection{Gas Chromatographic-Mass Spectral Analysis}

The essential oil was subjected to gas chromatography-mass spectrometry (GC-MS) analysis on an Agilent system consisting of a model 6890 gas chromatograph, a model 5973 mass selective detector (MSD), and an Agilent ChemStation data system. The GC column was a Hewlett Packard (HP-5ms) fused silica capillary with a (5\% phenyl)-methyl polysiloxane stationary phase $(30 \mathrm{~m} \times 0.25 \mu \mathrm{m}$ film thickness). The carrier gas was helium with a column head pressure of 7.07 psi and flow rate of $1.0 \mathrm{~mL} / \mathrm{min}$. Inlet temperature was $200{ }^{\circ} \mathrm{C}$ and MSD detector temperature was $280{ }^{\circ} \mathrm{C}$. The GC oven temperature program was used as follows: $40{ }^{\circ} \mathrm{C}$ initial temperature held for $10 \mathrm{~min}$; increased at $3{ }^{\circ} \mathrm{C} / \mathrm{min}$ to $200{ }^{\circ} \mathrm{C}$; increased $2{ }^{\circ} \mathrm{C} /$ min to $220{ }^{\circ} \mathrm{C}$. The sample was dissolved in $\mathrm{CH}_{2} \mathrm{Cl}_{2}$, and $1 \mu \mathrm{L}$ was injected using a splitless injection technique.

Identification of individual constituents of the essential oils was achieved based on their retention indices (determined with a reference to a homologous series of normal alkanes) and by comparison of their mass spectral fragmentation patterns (National Institute of Standards and Technology, NIST database/ChemStation data system, http://www.agilent.com/chem/nds) and with the literature [32]. 


\subsection{Antibacterial Screening}

Curcuma longa leaf oil was screened for antibacterial activity against Bacillus cereus (ATCC No. 14579), Staphylococcus aureus (ATCC No. 29213), Pseudomonas aeruginosa (ATCC No. 27853), and Escherichia coli (ATCC No. 10798). Minimum inhibitory concentrations (MICs) were determined using the microbroth dilution technique [33]. Dilutions of the samples were prepared in cation-adjusted Mueller Hinton broth (CAMHB) beginning with $50 \mu \mathrm{L}$ of $1 \% w / w$ solutions of samples in dimethylsulfoxide (DMSO) plus $50 \mu \mathrm{L}$ CAMHB. The sample solutions were serially diluted (1:1) in CAMHB in 96-well plates to give concentrations of 2500, 1250, 625, 313, 156, 78, 39, and $19.5 \mu \mathrm{g} / \mathrm{mL}$. Organisms at a concentration of approximately $1.5 \times 10^{8}$ colony-forming units $(\mathrm{CFU}) / \mathrm{mL}$ were added to each well. Plates were incubated at $37{ }^{\circ} \mathrm{C}$ for $24 \mathrm{~h}$; the final minimum inhibitory concentration (MIC) was determined as the lowest concentration without turbidity. Gentamicin was used as a positive antibiotic control; DMSO was used as a negative control.

\subsection{Antifungal Screening}

Antifungal activity was determined, as described above for bacteria, using Candida albicans (ATCC No.10231) in a yeast-nitrogen base growth medium with approximately $7.5 \times 10^{7} \mathrm{CFU} / \mathrm{mL}$. Amphotericin B was used as the positive control. An additional test for antifungal activity against Aspergillus niger (ATCC No. 16888) was determined as above using yeast mold (YM) broth inoculated with A. niger hyphal culture diluted to a McFarland turbidity of 1.0. Amphotericin B was the positive control.

\subsection{Cell Culture}

Human Hs578T breast ductal carcinoma cells (ATCC No. HTB-129) [34] were grown in a 3\% $\mathrm{CO}_{2}$ environment at $37{ }^{\circ} \mathrm{C}$ in DMEM with $4500 \mathrm{mg}$ glucose per liter of medium, supplemented with $10 \%$ fetal bovine serum, $10 \mu \mathrm{g}$ bovine insulin, 100,000 units penicillin and $10.0 \mathrm{mg}$ streptomycin per liter of medium, and buffered with $44 \mathrm{mM} \mathrm{NaHCO} 3, \mathrm{pH} 7.35$.

Human PC-3 prostatic carcinoma cells (ATCC No. CRL-1435) [35] were grown in a $3 \% \mathrm{CO}_{2}$ environment at $37{ }^{\circ} \mathrm{C}$ in RPMI-1640 medium with L-glutamine, supplemented with $10 \%$ fetal bovine serum, 100,000 units penicillin and $10.0 \mathrm{mg}$ streptomycin per liter of medium and buffered with $15 \mathrm{mM}$ Hepes and 23.6 mM NaHCO $3, \mathrm{pH} 7.30$.

\subsection{Cytotoxicity Screening}

Hs578T cells were plated into 96-well cell culture plates at $1.0 \times 10^{5}$ cells per well and PC-3 cells at $1.9 \times 10^{4}$ cells per well. The volume in each well was $100 \mu \mathrm{L}$ for both cell types. After $48 \mathrm{~h}$, supernatant fluid was removed by suction and replaced with $100 \mu \mathrm{L}$ growth medium containing either 2.5 or $1.0 \mu \mathrm{L}$ of DMSO solution of oils ( $1 \% w / w$ in DMSO), giving a final concentration of 250 or $100 \mu \mathrm{g} / \mathrm{mL}$, respectively, for each oil. Hs578T cells were tested with final concentrations at $250 \mu \mathrm{g} / \mathrm{mL}$ and PC-3 at a final concentration of $100 \mu \mathrm{g} / \mathrm{mL}$. Solutions were added to wells in four replicates. Medium controls and DMSO controls ( 25 or $10 \mu \mathrm{L} \mathrm{DMSO} / \mathrm{mL}$ ) were used. Tingenone ( 250 or $100 \mu \mathrm{g} / \mathrm{mL}$ ) was used as a positive control [36]. After the addition of the sample, plates were incubated for $48 \mathrm{~h}$ at $37{ }^{\circ} \mathrm{C}$; medium 
was then removed by suction, and $100 \mu \mathrm{L}$ of fresh medium was added to each well. In order to establish percent kill rates, the Cell Titer $96{ }^{\circledR} \mathrm{AQ}$ ueous Non-Radioactive Cell Proliferation assay was performed [37]. After colorimetric readings were recorded (using a Molecular Devices SpectraMAX Plus microplate reader, Sunnyvale, CA, USA, $490 \mathrm{~nm}$ ), average absorbances, standard deviations and percent kill ratios (\% killoil $\%$ kill DMSO) were calculated.

\subsection{Hierarchical Cluster Analysis}

A total of 20 C. longa leaf essential oil compositions from the published literature, as well as the composition from this study, were treated as operational taxonomic units (OTUs). The percentage composition of 21 major essential oil components ( $\alpha$-pinene, $\beta$-pinene, myrcene, $\alpha$-phellandrene, $\alpha$-terpinene, $p$-cymene, limonene, 1,8-cineole, $\gamma$-terpinene, terpinolene, linalool, terpinen-4-ol, $\alpha$-terpineol, $\beta$-caryophyllene, ar-curcumene, $\alpha$-zingiberene, $\beta$-sesquiphellandrene, ar-turmerone, $\beta$-turmerone, germacrone, and $\alpha$-turmerone) was used to determine the chemical relationship between the various $C$. longa leaf oil samples by agglomerative hierarchical cluster (AHC) analysis using the XLSTAT software, version 2015.4.01 (Addinsoft, Brooklyn, NY, USA). Pearson correlation was selected as a measure of similarity, and the unweighted pair-group method with arithmetic average (UPGMA) was used for cluster definition. The resulting dendrogram is shown in Figure 1.

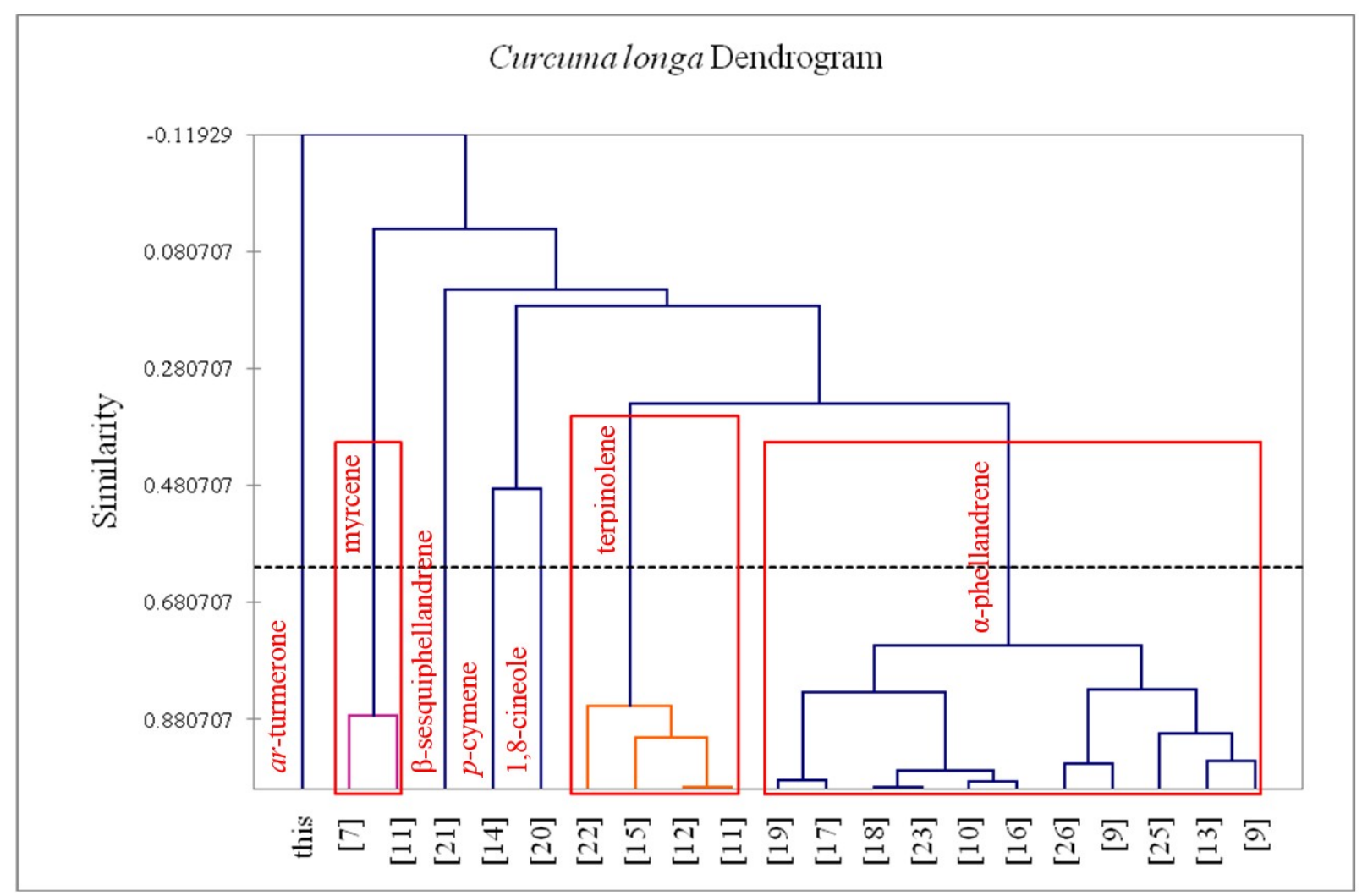

Figure 1. Dendrogram obtained from the agglomerative hierarchical cluster analysis of 21 Curcuma longa leaf essential oil samples. 


\section{Results and Discussion}

The leaf essential oil of $C$. longa was obtained in $0.67 \%(w / w)$ yield. Chemical analysis of the oil revealed 13 constituents representing $100 \%$ of the total essential oil composition (Table 1). The leaf oil was dominated by ar-turmerone (63.4\%), with lesser quantities of $\alpha$-turmerone (13.7\%) and $\beta$-turmerone (12.6\%). This turmerone-rich essential oil is very different from compositions of $C$. longa leaf oils published previously [7-26]. A cluster analysis of 20 published essential oil compositions in addition to the leaf oil in this present study (see Figure 1) shows seven different chemotypes: (1) an ar-turmerone-rich chemotype, represented by the leaf oil in this study; (2) a cluster dominated by $\alpha$-phellandrene, represented by 11 samples; (3) a terpinolene-rich chemotype; (4) a $\beta$-sesquiphellandrene-rich chemotype; (5) a $p$-cymene-rich chemotype; (6) a 1,8-cineole chemotype, and (7) a myrcene chemotype. Thus, there are wide variations in C. longa leaf essential oils, but the oil from southern Nigeria is the only one dominated by turmerones.

Table 1. Chemical composition of Curcuma longa leaf essential oil.

\begin{tabular}{cccccc}
\hline RI $^{\text {a }}$ & Compound & \% & RI $^{\text {a }}$ & Compound & $\%$ \\
\hline 977 & $\beta$-Pinene & 0.1 & 1524 & $\beta$-Sesquiphellandrene & 0.9 \\
1023 & $p$-Cymene & 1.6 & 1633 & $\beta$-Acorenol & 1.0 \\
1029 & 1,8 -Cineole & 1.6 & 1666 & $a r$-Turmerone & 63.4 \\
1452 & $\alpha$-Humulene & 0.2 & 1669 & $\beta$-Turmerone & 12.6 \\
1483 & $a r$-Curcumene & 2.0 & 1705 & $\alpha$-Turmerone & 13.7 \\
1487 & $\beta$-Ionone & 0.6 & 1770 & $(E)$ - $\alpha$-Atlantone & 1.0 \\
1509 & $\beta$-Bisabolene & 0.3 & - & Total Identified & 100 \\
\hline Retention Index determined in reference to a homologous series of $n$-alkanes on an HP-5ms column.
\end{tabular}

The abundance of turmerones and the exclusive non-detection of $\alpha$-phellandrene in the leaf oil sample from this work are noteworthy. $\alpha$-Phellandrene has been shown to occur in high concentrations in most published data on $C$. longa leaf essential oils. There are also notable differences in the chemical profiles of leaf oils from two different regions in Nigeria. The fresh leaf essential oil of C. longa grown in Ile-Ife, in southwest Nigeria, where there is predominately tropical rainforest vegetation, was reported to contain $\alpha$-phellandrene (47.7\%) and terpinolene (28.9\%) as its major constituents [19]. In the current study, the leaf was sourced from Mbaise in the southern zone of Nigeria, which is also tropical forest with comparable rainfall and temperatures. Although it is tempting to attribute the variations in chemical composition of the leaf oils to geographical location, leaf oil samples from Bhutan [9], Vietnam [13], and Malaysia [26], as well as several samples from India [9,10,16-18,23,25], all belong to the $\alpha$-phellandrene chemotype (see Figure 1). Conversely, a sample of the "Roma" cultivar from Orissa, India, was rich in terpinolene (87.8\%) [11], while a "Roma" sample from Lucknow was rich in myrcene (45.6\%) [7].

The results from the antimicrobial screening and the cytotoxicity screening of the leaf oil of C. longa are summarized in Table 2. The leaf oil demonstrated particularly strong antibacterial activity against the Gram-positive organisms B. cereus and $S$. aureus (MIC $=78 \mu \mathrm{g} / \mathrm{mL}$ ) and antifungal activity against $A$. niger $(\mathrm{MIC}=19.5 \mu \mathrm{g} / \mathrm{mL})$. The antimicrobial activities observed in $C$. longa leaf oil can be attributed to the major component ar-turmerone. Consistent with these results, ar-turmerone had previously shown strong antibacterial activity against Clostridium perfringens and weak inhibitory 
activity against Escherichia coli [38]. The antimicrobial results in this study showed that Gram-positive bacteria were more sensitive to the leaf oil of $C$. longa (Table 2). This result is consistent with those reported by other workers [39-42]. According to Alzoreky and Nakahara [42], Gram-negative bacteria are less susceptible to plant extracts due to lipopolysaccharides in their outer membrane. Similarly, turmerone-rich essential oils have shown antifungal activity [43,44], and ar-turmerone itself has shown antifungal activity against Aspergillus flavus [45].

Table 2. Biological activities of Curcuma longa leaf essential oil.

\begin{tabular}{|c|c|c|c|c|c|c|}
\hline \multicolumn{7}{|c|}{ Antimicrobial Activity (MIC, $\mu \mathrm{g} / \mathrm{mL})$} \\
\hline Sample & B. cereus & S. aureus & E. coli & P. aeruginosa & C. albicans & A. niger \\
\hline C. longa leaf EO & 78 & 78 & 312 & 625 & 312 & 19.5 \\
\hline Positive control & $1.22^{\mathrm{a}}$ & $0.61^{\mathrm{a}}$ & $2.44^{\mathrm{a}}$ & $1.22^{\mathrm{a}}$ & $0.61^{\mathrm{b}}$ & $0.61^{\mathrm{b}}$ \\
\hline \multicolumn{7}{|c|}{ Cytotoxic Activity } \\
\hline Sample & & Hs578T $^{c}$ & & & PC-3 ${ }^{d}$ & \\
\hline C. longa leaf EO & & $98.86 \pm 0.63$ & & & $97.94 \pm 2.05$ & \\
\hline Tingenone & & 100 & & & 100 & \\
\hline
\end{tabular}

The observed in vitro cytotoxicity against breast tumor (Hs578T) and prostate tumor (PC-3) cells is also consistent with the previously observed cytotoxicity of ar-turmerone. Thus, ar-turmerone has shown cytotoxic activity to HL-60, K-562, L-1210 [46], HeLa [47], U-937, and RBL-2H3 cells [48]. Furthermore, ar-turmerone has been shown to induce apoptosis coupled with DNA fragmentation in several cell lines [48-51].

\section{Conclusions}

High concentrations of turmerones were identified in the leaf essential oil of Curcuma longa from Mbaise, Nigeria. The composition of the leaf oil represents a new chemotype of this plant. The significant antibacterial, antifungal, and cytotoxic activities of the leaf oil may be attributed to the turmerone content. Due to the turmerone-rich essential oil, this chemotype of C. longa from southern Nigeria has promising therapeutic potential.

\section{Acknowledgments}

William N. Setzer is grateful to an anonymous private donor for the gift of the GC-MS instrumentation.

\section{Author Contributions}

Emmanuel E. Essien and Olusegun Ekundayo conceived and designed the project; Emmanuel E. Essien collected and hydrodistilled the essential oil; Jennifer Schmidt Newby and Tameka M. Walker performed the bioactivity assays; William N. Setzer analyzed the data; Emmanuel E. Essien and William N. Setzer wrote the manuscript. 


\section{Conflicts of Interest}

The authors declare no conflict of interest.

\section{References}

1. Chattopadhyay, I.; Biswas, K.; Bandyopadhyay, U.; Banerjee, R.K. Turmeric and curcumin: Biological actions and medicinal applications. Curr. Sci. 2004, 87, 44-53.

2. Jurenka, J.S. Anti-inflammatory properties of curcumin, a major constituent of Curcuma longa: A review of preclinical and clinical research. Altern. Med. Rev. 2009, 14, 141-153.

3. Mehra, A.; Bajpai, O.; Joshi, H. Diversity, utilization and sacred values of ethno-medicinal plants of Kumaun Himalaya. Trop. Plant Res. 2014, 1, 80-86.

4. Thapa S. Medico-ethnobotany of Magar community in Salija VDC of Parbat district, central Nepal. Our Nat. 2012, 10, 176-190.

5. Chen, Y.; Yu, J.; Fang, H. Studies on Chinese Curcuma. III. Comparison of the volatile oil and phenolic constituents from the rhizome and tuber of Curcuma longa. Zhong Yao Tong Bao 1983, 8, 27-29. (In Chinese)

6. Garg, S.N.; Bansal, R.P.; Gupta, M.M.; Kumar, S. Variation in the rhizome essential oil and curcumin contents and oil quality in the land races of turmeric Curcuma longa of north Indian plains. Flavour Fragr. J. 1999, 14, 315-318.

7. Bansal, R.P.; Bahl, J.R.; Garg, S.N.; Naqvi, A.A.; Sushil, K.; Kumar, S. Differential chemical composition of the essential oils of the shoot organs, rhizomes and rhizoids in the turmeric Curcuma longa grown in Indo-Gangetic plains. Pharm. Biol. 2002, 40, 384-389.

8. Akbar, A.; Kuanar, A.; Sandeep, I.S.; Kar, B.; Singh, S.; Mohanty, S.; Patnaik, J.; Nayak, S. GC-MS analysis of essential oil of some high drug yielding genotypes of turmeric (Curcuma longa L.). Int. J. Pharm. Pharmaceut. Sci. 2015, 7, 35-40.

9. Awasthi, P.K.; Dixit, S.C. Chemical composition of Curcuma longa leaves and rhizome oil from the plains of northern India. J. Young Pharm. 2009, 1, 312-316.

10. Behura, S.; Sahoo, S.; Srivastava, V.K. Major constituents in leaf essential oils of Curcuma longa L. and Curcuma aromatica Salisb. Curr. Sci. 2002, 83, 1312-1313.

11. Behura, S.; Srivastava, V.K. Essential oils of leaves of Curcuma species. J. Essent. Oil Res. 2004, 16, 109-110.

12. Chane-Ming, J.; Vera, R.; Chalchat, J.C.; Cabassu, P. Chemical composition of essential oils from rhizomes, leaves and flowers of Curcuma longa L. from Reunion Island. J. Essent. Oil Res. 2002, $14,249-251$.

13. Dūng, N.X.; Tuyêt, N.T.B.; Leclercq, P.A. Constituents of the leaf oil of Curcuma domestica L. from Vietnam. J. Essent. Oil Res. 1995, 7, 701-703.

14. Garg, S.N.; Mengi, N.; Patra, N.K.; Charles, R.; Kumar, S. Chemical examination of the leaf essential oil of Curcuma longa L. from the north Indian plains. Flav. Fragr. J. 2002, 17, 103-104.

15. Kiran Babu, G.D.; Shanmugam, V.; Ravindranath, S.D.; Joshi, V.P. Comparison of chemical composition and antifungal activity of Curcuma longa L. leaf oils produced by different water distillation techniques. Flav. Fragr. J. 2007, 22, 191-196. 
16. Kuanar, A.; Mohanty, S.; Panda, M.K.; Nayak, S. Essential oils from leaves of micropropagated turmeric. Curr. Sci. 2009, 96, 1166-1167.

17. Leela, N.K.; Tava, A.; Shafi, P.M.; John, S.P.; Chempakam, B. Chemical composition of essential oils of turmeric (Curcuma longa L.). Acta Pharm. 2002, 52, 137-141.

18. McCarron, M.; Mills, A.J.; Whittaker, D.; Sunny, T.P.; Verghese, J. Comparison of the monoterpenes derived from green leaves and fresh rhizomes of Curcuma longa L. from India. Flav. Fragr. J. 1995, 10, 355-357.

19. Oguntimein, B.O.; Weyerstahl, P.; Marschall-Weyerstahl, H. Essential oil of Curcuma longa L. leaves. Flav. Fragr. J. 1990, 5, 89-90.

20. Parveen, Z.; Nawaz, S.; Siddique, S.; Shahzad, K. Composition and antimicrobial activity of the essential oil from leaves of Curcuma longa L. Kasur variety. Indian J. Pharmaceut. Sci. 2013, 75, $117-122$.

21. Priya, R.; Prathapan, A.; Raghu, K.G.; Menon, A.N. Chemical composition and in vitro antioxidative potential of essential oil isolated from Curcuma longa L. leaves. Asian Pac. J. Trop. Biomed. 2012, 2, S695-S699.

22. Raina, V.K.; Srivastava, S.K.; Jain, N.; Ahmad, A.; Syamasundar, K.V.; Aggarwal, K.K. Essential oil composition of Curcuma longa L. cv. Roma from the plains of northern India. Flavour Fragr. J. 2002, 17, 99-102.

23. Raina, V.K.; Srivastava, S.K.; Syamsundar, K.V. Rhizome and leaf oil composition of Curcuma longa from the lower Himalayan region of northern India. J. Essent. Oil Res. 2005, 17, 556-559.

24. Sharma, R.K.; Mishra, B.P.; Sharma, T.C.; Bordloi, A.K.; Pathak, M.G.; Leclercq, P.A. Essential oil of Curcuma longa L. from Bhutan. J. Essent. Oil Res. 1997, 9, 589-592.

25. Sindhu, S.; Chempakam, B.; Leela, N.K.; Bhai, R.S. Chemoprevention by essential oil of turmeric leaves (Curcuma longa L.) on the growth of Aspergillus flavus and aflatoxin production. Food Chem. Toxicol. 2011, 49, 1188-1192.

26. Zaibunnisa, A.H.; Norashikin, S.; Mamot, S.; Osman, H. An experimental design approach for the extraction of volatile compounds from turmeric leaves (Curcuma domestica) using pressurised liquid extraction (PLE). LWT-Food Sci. Technol. 2009, 42, 233-238.

27. Rhyu, H.Y. Gas chromatographic characterization of sages of various geographic origins. J. Food Sci. 1979, 44,758-762.

28. Piccaglia, R.; Marotti, M.; Galletti, G.C. Characterization of essential oil from a Satureja montana L. chemotype grown in northern Italy. J. Essent. Oil Res. 1991, 3,147-152.

29. Shu, C.K.; Lawrence, B.M. Reasons for the variation in composition of some commercial essential oils. In Spices, Flavor Chemistry and Antioxidant Properties; ACS Symposium Series 660; Risch, S.J., Ho, C.T., Eds.; American Chemical Society: Washington, DC, USA, 1997; pp. 138-159.

30. Mohagheghzaded, A.; Ardakani, M.S.; Ghannadi, A. Linalol-rich essential oil of Zataria multiflora Boiss. (Lamiaceae). Flavour Frag. J. 2000, 15, 119-122.

31. British Pharmacopoeia Commission. British Pharmacopoeia; H.M. Stationery Office, Pharmaceutical Press: London, UK, 1980.

32. Adams, R.P. Identification of Essential Oil Components by Gas Chromatography/Mass Spectrometry, 4th ed.; Allured Publishing Corp.: Carol Stream, IL, USA, 2007. 
33. Sahm, D.H.; Washington, J.A. Antibacterial susceptibility tests: Dilution methods. In Manual of Clinical Microbiology, 5th ed.; Balows, A., Hausler, W.J., Herrmann, K.L., Isenberg, H.D., Shamody H.J., Eds.; American Society for Microbiology: Washington, DC, USA, 1991.

34. Hackett, A.J.; Smith, H.S.; Springer, E.L.; Owens, R.B.; Nelson-Rees, W.A.; Riggs, J.L.; Gardner, M.B. Two syngeneic cell lines from human breast tissues: The aneuploid mammary epithelial (Hs578T) and the diploid myoepithelial (Hs578Bst) cell lines. J. Natl. Cancer Inst. 1977, 58, 1795-1806.

35. Kaighn, M.E.; Narayan, K.S.; Ohnuki, Y.; Lechner, J.F.; Jones, L. Establishment and characterization of a human prostatic carcinoma cell line (PC-3). Investig. Urol. 1979, 17, 16-23.

36. Setzer, W.N.; Setzer, M.C.; Hopper, A.L.; Moriarity, D.M.; Lehrman, G.K.; Niekamp, K.L.; Morcomb, S.M.; Bates, R.B.; McClure, K.J.; Stessman, C.C.; et al. The cytotoxic activity of a Salacia liana species from Monteverde, Costa Rica, is due to a high concentration of tingenone. Planta Med. 1998, 64, 583.

37. CellTiter $96^{\circledR}$ AQueous One Solution Cell Proliferation Assay. Available online: https:/cn.promega.com/resources/protocols/technical-bulletins/0/celltiter-96-aqueous-onesolution-cell-proliferation-assay-system-protocol/ (accessed on 15 December 2015).

38. Lee, H.S. Antimicrobial properties of turmeric (Curcuma longa L.) rhizome-derived ar-turmerone and curcumin. Food Sci. Biotechnol. 2006, 15, 559-563.

39. Negi, P.S.; Jayaprakasha, G.K.; Rao, L.J.M.; Sakariah, K.K. Antibacterial activity of turmeric oil: A byproduct from curcumin manufacture. J. Agric. Food Chem. 1999, 47, 4297-4300.

40. Norajit, K.; Laohakunjit, N.; Kerdchoechuen, O. Antibacterial effect of five Zingiberaceae essential oils. Molecules 2007, 12, 2047-2060.

41. Giang, P.M.; Huong, V.N.; Son, P.T. Antimicrobial activity of sesquiterpene constituents from some Curcuma species of Vietnam. Vietnamese J. Chem. 2000, 38, 91-94.

42. Alzoreky, N.S.; Nakahara, K. Antibacterial activity of extracts from some edible plants commonly consumed in Asia. Int. J. Food Microbiol. 2003, 80, 223-230.

43. Jankasem, M.; Wuthi-udomlert, M.; Gritsanapan, W. Antidermatophytic properties of ar-turmerone, turmeric oil, and Curcuma longa preparations. ISRN Dermatol. 2013, 2013, 250597.

44. Ferreira, F.D.; Mossini, S.A.G.; Ferreira, F.M.D.; Arrotéia, C.C.; da Costa, C.L.; Nakamura, C.V.; Junior, M.M. The inhibitory effects of Curcuma longa L. essential oil and curcumin on Aspergillus flavus Link growth and morphology. Sci. World J. 2013, 2013, 343804.

45. Dhingra, O.D.; Jham, G.N.; Barcelos, R.C.; Mendonça, F.A.; Ghiviriga, I. Isolation and identification of the principal fungitoxic component of turmeric essential oil. J. Essent. Oil Res. 2007, 19, 387-391.

46. Baik, K.U.; Jung, S.H.; Ahn, B.Z. Recognition of pharmacophore of ar-turmerone for its anticancer activity. Arch. Pharmacal Res. 1993, 16, 254-256.

47. Schmidt, E.; Ryabchenko, B.; Wanner, J.; Jäger, W.; Jirovetz, L. Cytotoxic active constituents of essential oils of Curcuma longa and Curcuma zanthorrhiza. Nat. Prod. Commun. 2015, 10, 139-141.

48. Ji, M.; Choi, J.; Lee, J.; Lee, Y. Induction of apoptosis by ar-turmerone on various cell lines. Int. J. Mol. Med. 2004, 14, 253-256.

49. Paek, S.H.; Kim, G.J.; Jeong, H.S.; Yum, S.K. Ar-turmerone and $\beta$-atlantone induce internucleosomal DNA fragmentation associated with programmed cell death in human myeloid leukemia HL-60 cells. Arch. Pharmacal Res. 1996, 19, 91-94. 
50. Aratanechemuge, Y.; Komiya, T.; Moteki, H.; Katsuzaki, H.; Imai, K.; Hibasami, H. Selective induction of apoptosis by ar-turmerone isolated from turmeric (Curcuma longa L) in two human leukemia cell lines, but not in human stomach cancer cell line. Int. J. Mol. Med. 2002, 9, 481-484.

51. Cheng, S.B.; Wu, L.C.; Hsieh, Y.C.; Wu, C.H.; Chan, Y.J.; Chang, L.H.; Chang, C.M.J.; Hsu, S.L.; Teng, C.L.; Wu, C.C. Supercritical carbon dioxide extraction of aromatic turmerone from Curcuma longa Linn. induces apoptosis through reactive oxygen species-triggered intrinsic and extrinsic pathways in human hepatocellular carcinoma HepG2 cells. J. Agric. Food Chem. 2012, 60, 9620-9630.

(C) 2015 by the authors; licensee MDPI, Basel, Switzerland. This article is an open access article distributed under the terms and conditions of the Creative Commons Attribution license (http://creativecommons.org/licenses/by/4.0/). 